\title{
Aquisição da Linguagem: Considerações da Perspectiva da Interação Social
}

\author{
Lucivanda Cavalcante Borges ${ }^{12}$ \\ Nádia Maria Ribeiro Salomão \\ Universidade Federal da Paraíba
}

\begin{abstract}
Resumo
Os estudos sobre a influência dos fatores sociais na aquisição da linguagem tiveram grande impulso com as críticas às considerações de Chomsky de que havia uma "pobreza dos estímulos" e, portanto, a criança não poderia adquirir a linguagem a partir do meio social. Autores da perspectiva da Interação Social no estudo da linguagem desafiam a posição chomskiana, e evidenciam a importância da interação social para a aquisição da linguagem, especialmente as relações da criança com a mãe. Essas relações representam um sistema dinâmico, segundo o qual ambos contribuem com suas experiências e conhecimentos para o curso da interação. A linguagem é entendida, nesta perspectiva, enquanto comunicação, e portanto é anterior ao surgimento das palavras. Neste trabalho, pretende-se apresentar as explicações desta perspectiva teórica sobre o processo de aquisição da linguagem infantil. Serão discutidos os efeitos da fala materna (motherese) e sua influência na aquisição da linguagem por parte da criança, assim como os diferentes estilos de input lingüístico, considerando também a importância das características da criança na interação.

Palavras-chave: Linguagem infantil; interação social; input lingüístico.
\end{abstract}

Language Acquisition: Explanations of the Social Interaction Perspective

\begin{abstract}
The studies on the influence of social factors on language acquisition were largely influenced by the criticism made to Chomsky's ideas. Researchers following the social interaction perspective disagree with Chomsky and stress the influence of input on language acquisition. This perspective recognises the role of social interaction between adult and child, especially the mother, in the development of infant language. The relationship is characterised by a bidirectional model in which both parts contribute to the course of interaction. In this perspective, language is considered communication, and so initiate before the emission of words. The aim of this paper is to present the explanations of Social Interaction perspective regarding children's language acquisition. Maternal speech styles (motherese) and their influence on child's language, and different input styles are discussed, considering the child's characteristics.

Keywords: Child language; social interaction; linguistic input.
\end{abstract}

A linguagem é considerada a primeira forma de socialização da criança, e, na maioria das vezes, é efetuada explicitamente pelos pais através de instruções verbais durante atividades diárias, assim como através de histórias que expressam valores culturais. A socialização através da linguagem pode ocorrer também de forma implícita, por meio de participação em interações verbais que têm marcações sutis de papéis e status (Ely \& Gleason, 1996).

Desta forma, através da linguagem a criança tem acesso, antes mesmo de aprender a falar, a valores, crenças e regras, adquirindo os conhecimentos de sua cultura. À medida que a criança se desenvolve, seu sistema sensorial - incluindo a visão e audição - se torna mais refinado e ela alcança um nível lingüístico e cognitivo mais elevado, enquanto seu campo de socialização se estende, principalmente quando ela entra para a escola e tem maior oportunidade de interagir

\footnotetext{
${ }^{1}$ Pesquisa financiada pela CAPES

${ }^{2}$ Endereço para correspondência: Av. Adélia Franco, 3662, 502, 40040 020, Aracaju, SE. Fone (79) 2321092, 91391124.E-mail: luci.cborges@ig.com.br
}

com outras crianças. De acordo com Garton (1992), quanto mais cedo a criança se envolve nas relações sociais, mais benefícios obterá a curto ou longo prazo, tendo em vista as experiências e aprendizagens que resultam de tais interações.

A linguagem corresponde ainda a uma das habilidades especiais e significativas dos seres humanos, compreendida como um sistema de sinais de duas faces - significante e significado. O significante refere-se ao aspecto formal da linguagem, e é constituído pela junção hierárquica dos elementos fonemas, palavras, orações e discurso. Os fonemas integram palavras, as palavras combinam-se em orações, e as orações se enquadram no discurso. O significado, por outro lado, refere-se ao aspecto funcional da linguagem, considerado como o responsável pela comunicação no meio social (Luque \& Villa, 1995). Segundo Villa (1995), este conceito foi introduzido nos estudos sobre a aquisição da linguagem devido à necessidade de se considerar o papel semântico da fala, visto que a sintaxe por si só não explicaria as produções lingüísticas que são sintaticamente corretas porém não são empregadas na fala. 
Em meados dos anos 1970, incorporou-se aos estudos da linguagem a abordagem da pragmática, que enfatiza os fatores comunicativos da linguagem, devido à necessidade de se relacionar a linguagem com o contexto da fala. De acordo com Austin (1952/1990), a linguagem deve ser analisada no ato da fala, no contexto social e cultural no qual é usada, com uma determinada intenção e de acordo com certas normas e convenções.

O estudo da pragmática relaciona os aspectos fonológicos, semânticos e sintáticos da fala com o contexto no qual esta ocorre, explicando seus diferentes usos. Conhecendo-se o contexto onde ocorre a fala, assinala Villa (1995), é possível compartilhar o tema sem necessariamente verbalizar a intenção do indivíduo. A este respeito, pode-se exemplificar, uma criança que estende a mão ao ver sua mãe comendo um doce, não necessariamente precisa verbalizar seu desejo pelo doce, sendo o seu gesto suficiente para o entendimento da mãe.

A pragmática tem sido enfatizada pela perspectiva da interação social nas explicações sobre a aquisição da linguagem infantil (Conti-Ramsden, 1994; Pine, 1994). Segundo esta perspectiva, a criança adquire a linguagem a partir da interação dos aspectos biológicos com os processos sociais. A premissa fundamental é a noção de que a interação social é um componente necessário para a criança adquirir a linguagem. Assim, as relações da criança com os adultos são fundamentais para o desenvolvimento das habilidades lingüísticas, visto constituir-se como um sistema dinâmico, através do qual ambos contribuem com suas experiências e conhecimentos para o curso da interação, estabelecendo uma relação recíproca e bidirecional.

É com base nesta perspectiva teórica, a da interação social, que o presente trabalho tem por objetivo discutir como se processa a aquisição da linguagem; quais estilos lingüísticos presentes na interação adulto-criança contribuem para que esta adquira a linguagem; de que maneira esses estilos influenciam a participação da criança na conversação.

Analisar essas questões constitui-se importante para uma melhor compreensão do papel do adulto e da participação da criança no processo de aquisição da linguagem. Para tanto, analisa-se ao longo desse trabalho, as intenções comunicativas da criança desde um período muito precoce de seu desenvolvimento, e a influência da fala materna, considerada característica das interlocuções adulto-criança. Compara-se ainda, as explicações da teoria inatista com a teoria da interação social sobre a linguagem, discutindo-se o papel do input lingüístico (experiências lingüísticas que a criança recebe de seu meio social) nesse processo.

Por fim, apresenta-se as considerações finais, demonstrando a importância de se compreender melhor a dinâmica dos primeiros processos interacionais adulto- criança, assim como a influência dos fatores socioculturais para se explicar a aquisição da linguagem.

\section{Intenções Comunicativas da Criança e Análise da Fala Materna}

A ênfase na relação adulto-criança no processo de aquisição da linguagem tem influência especialmente dos trabalhos de Austin (1952/1990) e Searle (1969/1995), sobre os atos de fala. $\mathrm{O}$ advento desses estudos ressaltou a importância da relação entre as intenções comunicativas e os primeiros estágios da linguagem formal. Essa importância tinha como pressuposto básico a consideração de que a habilidade social e comunicativa da criança era mais precoce do que sua habilidade para a linguagem formal.

Neste sentido, a participação do adulto como interlocutor linguisticamente mais habilitado exerce o papel de mostrar-se sensível às intenções comunicativas da criança, buscando aproximar o nível lingüístico desta ao seu (Garton, 1992).

A constatação de que as crianças apresentam intenções comunicativas desde seus primeiros meses de vida influenciou os estudiosos da linguagem a pesquisar a fala espontânea da criança em interação com seus pais.

No entanto, essas pesquisas receberam críticas dos inatistas, especialmente de Chomsky (1973), os quais argumentavam que a fala dos adultos apresentada às crianças é mal formada, limitada e contém hesitações, e portanto, a criança não poderia aprender a linguagem a partir de fontes externas. Para Chomsky, a linguagem teria origem em mecanismos inatos.

Em resposta aos inatistas, os estudiosos da teoria da interação social passaram a realizar os primeiros estudos sistemáticos sobre a fala materna apresentada às crianças (Phillips, 1973; Snow, 1977). Eles afirmavam que os pais, especialmente as mães, apresentam uma forma especial de falar a seus filhos, forma essa caracterizada por um léxico e estruturas sintáticas diferentes daquela utilizada na fala com os adultos. Essa diferença ocorre sob variadas dimensões:

a) as mães utilizam procedimentos facilitadores da compreensão, tendem a enfatizar as palavras essenciais numa frase, diminuir a velocidade da fala e repetir o que disseram, caso a criança não tenha entendido (Snow, 1972);

b) as mães utilizam uma fala sintaticamente mais simples, com vocabulário e complexidade preposicional limitados (Phillips, 1973; Snow, 1972);

c) a linguagem materna é restrita ao 'aqui e agora', conjugada no tempo presente e referente a objetos visíveis e comentários sobre atividades contínuas (Snow, 1977);

d) as mães empregam um número de características especiais na fala apresentada à criança, cuja intenção é envolvê-la na interação, clarificando e elevando sua contribuição (Snow, 1977). 
Essas pesquisas demonstraram que as mães, de uma forma geral, utilizam uma fala simples, repetitiva, gramatical e semanticamente ajustada ao nível de compreensão e interesse da criança.

Ademais, outras pesquisas (Villa, 1995) demonstram as intenções comunicativas de crianças desde idades muito precoces. Os gestos, as expressões faciais, o olhar do bebê constituem formas de comunicar intenções. Combinado à comunicação não verbal, o bebê passa a produzir vocalizações, com entonações marcadas. Assim, os adultos compreendem mais facilmente suas intenções e podem conversar com elas. Esse período é conhecido como protoconversação ou protolinguagem.

Após os resultados dessas pesquisas sobre a fala materna dirigida às crianças, os inatistas argumentaram que, pelo fato da fala materna apresentar-se muito simples, esta constituise uma barreira ao avanço da linguagem da criança. Entretanto, vale ressaltar que esta simplicidade apresentada na fala materna dependerá do nível lingüístico da criança, pois as mães adequam seu nível de fala ao nível lingüístico da criança, de forma a envolvê-la na interação (Furrow, Nelson \& Benedict, 1979). Pode-se considerar aqui a posição de Snow (1977), que explica ser a simplicidade sintática da fala materna um artefato da simplicidade semântica, ou seja, a fala materna apresenta-se sintaticamente simples para que a criança a compreenda, e é uma fala que corresponde ao nível de interesses, compreensão, habilidades cognitivas e lingüísticas da criança.

Ademais, como apontam L. Gleitman, Newport e H. Gleitman (1984), nem as sentenças muito simples, nem as sentenças muito complexas seriam mais informativas para a criança, uma vez que esta seleciona o material lingüístico disponível de acordo com seu nível de compreensão.

Este tipo de fala apresentada à criança é conhecido como "motherese" (manhês), e segundo os defensores da perspectiva da interação social dos estudiosos da linguagem, tem a função de envolvê-la na interação, no intuito de principalmente se comunicar com ela. É considerada um tipo de input característico da fala das mães, que apresentamse sensíveis ao nível lingüístico da criança, às suas habilidades sociais e cognitivas, assim como às idéias e interesses da mesma, incorporando-os ao seu próprio modelo de produção de fala (Pine, 1994).

Desta forma, a figura materna exerce uma influência particularmente privilegiada no desenvolvimento da linguagem da criança, representando suas primeiras fontes de cuidado e atenção (Ely \& Gleason, 1996). Segundo Lieven (1994), a direção dessa influência não é universal, visto refletir as práticas culturais endereçadas às crianças, ou seja, em algumas culturas as crianças ficam sob os cuidados de um irmão mais velho, por exemplo. Entretanto, é importante ressaltar que esse estilo de fala - motherese não é utilizado apenas pela mãe exatamente, mas por aquelas pessoas que exercem a função materna, que podem ser tanto a mãe real ou outra pessoa que cuida da criança.

\section{Os Efeitos da Fala Motherese}

$\mathrm{Na}$ interação mãe-criança, o estilo da fala motherese permite "um conjunto de expectativas comuns aos participantes (criança e adulto), e torna possível a cada um reconhecer o sinal do outro, antecipando sua própria resposta" (Villa, 1995, p. 73). Ainda mais, a oportunidade dessas experiências entre a mãe e a criança nos primeiros anos de vida estabelece muito do que pode ser aprendido posteriormente pela criança.

Maratsos (1983) ressalta que a fala motherese é muito importante para a criança nos seus primeiros anos de vida, visto que a criança não pode responder a sentenças muito complexas. De acordo com esse autor, os enunciados maternos mais prováveis de serem seguidos por uma resposta imediata da criança são aqueles caracterizados por sentenças pequenas e simples. As sentenças longas e complexas têm um efeito inibidor da responsividade das crianças.

As sentenças complexas enfraquecem a função comunicativa do diálogo, uma vez que torna difícil sua compreensão por parte da criança que se encontra num nível lingüístico inferior. Consequentemente, produz-se um modelo não efetivo de interação entre a criança e seu ambiente lingüístico, o que pode despertar problemas no desenvolvimento da linguagem da criança. Neste sentido, faz-se necessário que a fala materna apresentada à criança seja simples e curta, porém corresponda a um nível um pouco mais elevado que o da criança, de forma que torne possível sua participação no diálogo e promova o seu avanço lingüístico (Maratsos, 1983).

Ainda referindo-se ao nível de complexidade da fala materna podemos destacar as considerações de Vygotsky (1978/1984) e Bruner (1983). Vygotsky atribuiu o nome de "zona de desenvolvimento proximal" à capacidade da criança funcionar entre dois níveis de desenvolvimento: o seu nível real e o nível potencial (que pode ocorrer com a colaboração de um companheiro mais experiente). Segundo esse autor, um companheiro mais avançado estrutura a interação que excede o nível de desenvolvimento real da criança, aproximando-a de seu nível potencial, ajudando-a a avançar de um nível para outro. Assim, a mãe exerce o papel do companheiro dotado de um nível de desenvolvimento mais elevado que o da criança, propiciando a aproximação do nível lingüístico (potencial) desta ao seu.

A “zona de desenvolvimento proximal" é assim uma medida da aprendizagem potencial da criança e implica a 
colaboração entre os participantes em interação social, cada um exercendo uma contribuição no processo de aprendizagem. Constitui, ainda, um processo dinâmico através do qual a contribuição do adulto é alterada em função do progresso na competência e no entendimento da criança (Vygotsky, 1978/1984).

De acordo com Barnes, Gutfreund, Satterly e Wells (1983), Bruner utiliza termos diferentes para descrever basicamente a mesma explicação que Vygotsky (1978/ 1984) atribui à participação do adulto no desenvolvimento da criança. Para Bruner (1997), o papel do adulto em promover o desenvolvimento da linguagem da criança deve ser visto em termos interacionais, no sentido que o adulto promove o scaffolding (edificação), através do qual a criança pode construir progressivamente comunicações funcionalmente mais efetivas e formalmente mais elaboradas. Esse autor concorda com os pressupostos pragmáticos de que a criança aprende a usar a linguagem, isto é, a se comunicar, antes mesmo de aprender seus aspectos formais.

O termo scaffolding deriva do conceito de "zona de desenvolvimento proximal", elaborado por Vygotsky (1978/1984), e corresponde a uma "descrição metafórica de um processo de ensino que facilita a aprendizagem da criança" (Garton, 1992, p. 44). Nesse processo de ensino, a mãe responde contingentemente ao enunciado produzido pela criança, encorajando-a e instruindo-a a usar a linguagem de forma mais elaborada e funcionalmente correta, e retirando esse apoio gradualmente à medida que a criança se desenvolve.

Bruner (1983) explica a aquisição da linguagem a partir de dois mecanismos: um é equivalente ao Language Aquisition Device - LAD, correspondendo a uma força interna (push) que impulsiona a criança a aprender a linguagem. O outro é a força que absorve (pull) a linguagem do meio social, através do estímulo encorajador (scaffolding) da pessoa que mais interage com a criança, somada ao contexto constante e reconhecível no qual a linguagem é usada. Essa estrutura recebe o nome de Language Acquisition Support System (LASS), e é considerada essencial para que a criança aprenda a linguagem.

Em resumo, Vygotsky e Bruner, embora seguindo abordagens diferentes, concordam que a fala materna apresentada à criança relaciona-se ao nível de habilidade lingüística e cognitiva da mesma, de forma a contribuir para o seu desenvolvimento.

Autores como Snow (1977) e Pine (1994) enfatizam $\mathrm{o}$ aspecto conversacional da fala motherese, alegando que a mãe não conversa para a criança, mas com a criança. Porém, de acordo com Pine, esse não é o único objetivo da fala motherese. Segundo esse autor, devido à tentativa de estabelecer a comunicação, a mãe busca relacionar sua complexidade de fala ao nível lingüístico da criança, pois se preocupa mais com o nível de compreensão lingüística dela do que com o nível de produção. Neste sentido, argumenta Pine, a fala motherese não pode ser abordada através de um simples modelo conversacional, o que torna necessário o uso de uma abordagem multidimensional.

O fato de não se considerar uma abordagem multidimensional nos efeitos da fala motherese tem sido apontado por Pine (1994) como um dos fatores responsáveis pela falta de consistência entre os resultados de diferentes estudos, ocasionando incertezas quanto aos efeitos desse tipo de fala. Segundo esse autor, os efeitos potencialmente facilitadores da motherese não são diretos. Ademais, problemas metodológicos contribuem para as inconsistências entre os resultados dos estudos nessa área. Esses problemas incluem a falta de controle das relações entre a fala motherese e a idade e o nível lingüístico da criança (Furrow \& cols., 1979).

Segundo Gleitman e colaboradores (1984), o controle desses aspectos, idade e nível lingüístico da criança, é importante devido ao fato de que a fala motherese deve ser entendida em termos das disposições da própria criança para organizar e utilizar a informação lingüística, pois a criança faz diferentes usos da linguagem que recebe, em diferentes pontos de seu desenvolvimento. Assim, se nos primeiros estágios lingüísticos a criança está aprendendo o vocabulário básico e a expressar formas semânticas simples e funções pragmáticas, a fala motherese, enquanto estilo de input simples, poderá ter um efeito facilitador nesse processo. Porém, se a criança encontra-se num nível lingüístico de aquisição de regras sintáticas, provavelmente será necessário um estilo de input mais complexo.

Neste sentido, a natureza da linguagem apresentada à criança varia em complexidade, em função lingüística e em forma, dependendo do status desenvolvimental da criança, do seu nível de participação e do papel na interação.

Questiona-se, ainda, se é a quantidade ou a qualidade de fala apresentada à criança que prediz a rápida aquisição da linguagem. Os estudos de Barnes e colaboradores (1983), com uma amostra de 32 crianças de 24 meses, distribuídas igualmente em função do gênero e observadas em situação natural, demonstraram que a quantidade de fala apresentada à criança foi o aspecto de maior predição positiva de muitos aspectos do desenvolvimento semântico e sintático. Uma das formas de se medir a quantidade de fala apresentada à criança, assim como o nível lingüístico da própria criança, é através do cálculo do tamanho médio do enunciado - MLU (do inglês Mean Length Utterance). Alguns autores (Bates, Dale \& Thal, 1997) criticam o uso do MLU como uma medida geral do estudo da linguagem, porém esta continua sendo a medida de desenvolvimento lingüístico mais utilizada. 
Enfim, pode-se observar que, de um modo geral, para a perspectiva da interação social dos estudiosos da linguagem, as informações ou experiências do ambiente lingüístico da criança são consideradas como aspectos de muita importância na aquisição da linguagem. Estas informações ou experiências recebem o nome de input. O imput lingüístico refere-se a "toda experiência proporcionada pelo uso que os demais fazem da linguagem em suas interações e, especialmente, ao comunicar-se com o próprio sujeito, é sua principal fonte de informação sobre a própria linguagem, sobre a cultura, e sobre o papel da linguagem na cultura" (Luque \& Villa, 1995, p. 157). O input lingüístico caracteriza uma comunidade ou grupo falante, veicula seus modelos socioculturais e exerce uma pressão socializadora sobre o uso individual da linguagem no interior dessa comunidade ou grupo, visto ser sensível às diferenças sociais.

Snow (1996) assinala que não há um consenso entre autores no que diz respeito a quais estilos de input são favoráveis à aquisição da linguagem por parte da criança. Entretanto, existe, por outro lado, um grande número de evidências sobre quais estilos de input podem facilitar o desenvolvimento lingüístico da criança e quais podem inibir seu percurso "normal". Estas evidências devem ser interpretadas com cautela, visto que não se tem claramente definido quais fatores são a causa e quais fatores são os efeitos, ou seja, se é o estilo do input que influencia o desenvolvimento da linguagem da criança, ou se são as características presentes na criança que influenciam a qualidade do input (Rice, 1989).

\section{Estilos de Input e seus Efeitos na Aquisição Lingüística}

Dentre as características do input que podem facilitar o desenvolvimento da linguagem, a contingência da fala materna com o enunciado prévio da criança tem sido apontada com destaque por vários autores (Conti-Ramsden, 1994; HoffGinsberg, 1991; Rice, 1989). A contingência pode ser definida, segundo Rice (1989), como a combinação ou articulação imediata da expressão do adulto ao conteúdo ou tópico das expressões da criança, de forma a oferecer uma continuidade na conversação.

Segundo Damast, Tamis-LeMonda e Bornstein (1996), não é meramente a freqüência de comportamentos maternos interativos que facilita o desenvolvimento lingüístico da criança, mas ambos, a contingência e a adequação do comportamento da mãe ao contexto de contínua interação.

A importância deste tipo de fala é apresentada por autores como Gallaway e Woll (1994) e Conti-Ramsden (1994), que afirmam haver uma relação entre o progresso rápido da linguagem e a rica disponibilidade da fala semanticamente contingente. Os resultados de Vandell e
Wilson (1987) apresentam-se na mesma direção. Esses autores realizaram um estudo com 3 grupos de díades - mãe-criança, criança-colega, criança-irmão, totalizando 26 crianças, divididas igualmente em função do gênero e da classe social (média e baixa), na faixa etária de 6 a 9 meses. Os resultados indicaram que as mães que respondem contingentemente ao comportamento de seus filhos lhes proporcionam mais experiências de tomar a direção na conversação, assim como estabelecem uma maior segurança na relação mãe-criança.

Esta importância foi demonstrada ainda nos resultados do estudo de Salomão (1996), os quais indicaram que as mães que respondem ao comportamento verbal da criança dando continuidade ao seu tópico de interesse, oferecem a ela oportunidade de maior participação na conversação. Ademais, autores como Sheppard e Willoughby (1975) assinalam que as crianças que vivem relativamente isoladas deste estilo de input lingüístico freqüentemente mostram retardo na linguagem.

Dentre outras características da fala materna direcionada à criança, descritas como propiciadoras do desenvolvimento da linguagem, pode-se encontrar: apresentar feedbacks à criança (especialmente os de repetição e reformulação de seu enunciado); e fazer solicitaçôes à criança (especialmente solicitar clarificações e emitir-lhe questões) (Ely \& Gleason, 1996).

No que diz respeito aos feedbacks maternos dos enunciados infantis, os resultados do estudo de Fagot e Hagan (1991), realizados com 296 crianças na faixa etária de 18 meses a 5 anos de idade, sendo 42 meninas e 50 meninos acompanhados de seus irmãos, com mães de nível educacional superior, mostraram que este estilo de fala é encorajador do esforço comunicativo das crianças. Segundo Bakhtin, (1981, citado em Ely \& Gleason, 1996), o feedback de repetição da fala da criança oferece-lhe a oportunidade de reinterpretar seu comportamento de fala anteriormente proferida, e é efetivo em manter a criança na conversação, favorecendo-lhe o desenvolvimento da linguagem.

Geralmente o adulto repete modificando, enriquecendo ou corrigindo o enunciado infantil, e a quantidade desta repetição varia de acordo com a idade da criança (Aimard, 1986). Esta repetição é também conhecida por expansão ou reformulação e sua ocorrência pode ajudar na aquisição da linguagem por parte da criança, na medida em que demonstra-lhe a relação entre as suas formas de linguagem mais primitivas e as formas corretas do adulto, preenchendo os elementos omitidos, e ilustrando-lhe assim, a sintaxe (Hoff-Ginsberg \& Shatz, 1982).

A este respeito, pode-se citar o estudo de Nelson (1977), cujo objetivo era verificar a importância da reformulação sobre o enunciado da criança. Para tanto, este autor expôs um grupo de crianças a uma extensa quantidade de fala reformulada e comparou-o com outro grupo que recebeu a 
mesma quantidade de conversa, porém sem reformulação. Os resultados mostraram que as crianças expostas à fala reformulada usaram formas mais complexas em suas conversas durante o experimento do que as crianças do outro grupo.

Esse feedback de expansão ou reformulação é considerado por Sokolov e Snow (1994) como um dos mais eficazes estilos de imput materno no processo de aquisição da linguagem, uma vez que apresenta às crianças versões corrigidas ou alternativas de seu enunciado, demonstrando que o feedback. pode ser usado pela criança. Ademais, estudos como o de Furrow e colaboradores (1979), com uma amostra de 27 díades mãe-criança primogênita, na faixa etária de 1 ano e 6 meses a 2 anos e 3 meses, pertencentes à classe média e raça branca, falantes da língua inglesa, têm mostrado haver uma correlação positiva entre as expansões/reformulações maternas e o desenvolvimento da linguagem da criança.

Snow (1989) considera a reformulação dos enunciados infantis como uma das quatro características de interação social que são potencialmente facilitadoras do desenvolvimento lingüístico da criança. As outras três características são a fala fine-tuning (sintonia entre a fala materna e a fala da criança), o feedback negativo (corrigir os enunciados gramaticalmente incorretos) e a atenção conjunta (períodos em que mãe e criança compartilham uma mesma atividade). Segundo Gleitman e colaboradores (1984), esse estilo de fala exerce um papel importante na aquisição da linguagem, especialmente na aquisição da sintaxe.

De acordo com Conti-Ramsden (1990), a relativa ausência de reformulações no input materno tem sido apontada como um dos fatores explicativos no atraso da fala das crianças. Em seu estudo publicado em 1990, comparou 28 díades mãe-criança, sendo 14 crianças com atraso na linguagem, na faixa etária entre 3 anos e 6 meses a 5 anos e 4 meses, e 14 crianças com desenvolvimento normal da linguagem, na faixa etária entre 1 ano e 7 meses a 2 anos e 3 meses. Essas díades pertenciam à classe média e à raça branca, e eram moradoras de uma cidade do sudoeste dos Estados Unidos. Os resultados indicaram que as crianças com atraso na linguagem receberam menos reformulações complexas, através do imput de suas mães, do que as crianças com desenvolvimento normal da linguagem. Esse resultado evidencia a relação bidirecional mãe-criança, uma vez que o estilo de fala materna apresentou-se adequado ao nível lingüístico da criança.

Nelson, Welsh, S. M. Camarata, Butkovsky e M. Camarata (1995) assinalam que, embora os estudos mostrem que as reformulações favorecem a aquisição da linguagem por parte da criança, se essas reformulações não apresentarem um caráter desafiador, estimulador da atenção e participação da criança, não alcançarão um efeito positivo, mesmo que sua freqüência seja elevada.

A explicação para esse fato é dada por Nelson e colaboradores (1995), a partir da "teoria da aprendizagem do efeito raro" (Rare Event Learning - REL). Tal teoria tem como pressuposto a consideração de que a criança, ainda muito jovem, tem a habilidade de processar eficientemente e aprender estruturas lingüísticas que são apresentadas mesmo que raramente em seu input lingüístico, desde que essas estruturas apresentem-se num nível lingüístico um pouco mais elevado que o seu, isto é, que sejam altamente processáveis, capazes de sustentar a atenção da criança. Nelson e colaboradores (1995) consideram que as reformulações e a continuação do tópico de interesse da criança correspondem a condições nas quais as estruturas são altamente processáveis.

O outro estilo lingüístico considerado estimulador da aquisição lingüística é a solicitação materna, especialmente solicitar clarificação. Solicitar clarificaşão é considerado por Demetras, Post e Snow (1986) como um estilo de fala utilizado geralmente após enunciados mal elaborados pela criança, e que apresenta a função de auxiliar a criança a reformular e reorganizar as regras do sistema gramatical. É também indicado por Hirsh-Pasek, Treiman e Schneiderman (1984) como um mecanismo poderoso para promover correções e mudanças na linguagem produtiva da criança.

Ainda como solicitações maternas, os enunciados com a função de emitir questões, especialmente questões abertas, têm sido apontados pelos estudos de McCabe e Peterson (1991) como formando um estilo de input que influencia a criança a apresentar produções e narrativas mais longas e coerentes. Esse estilo de input é considerado um dos mais efetivos na iniciativa da conversação, na medida em que pode ser visto como uma forma de passar o turno da conversação para a criança. Entretanto, é necessário como aponta Aimard (1986), apresentar a questão e a resposta ao mesmo tempo, oferecendo à criança espaço para que possa responder.

Enfim, no processo de interação mãe-criança é importante que a mãe seja responsiva à criança, oferecendolhe atenção e respostas às suas necessidades. Segundo Scarr e Eisenberg (1993), as crianças que têm cuidadores mais responsivos e de maior envolvimento apresentam comportamentos mais exploratórios e mais positivos, além de apresentarem melhor relacionamento entre pares. Para Beckwith, Rodning e Cohen (1992), a responsividade encontra-se associada à competência intelectual e acadêmica da criança, a poucos problemas emocionais e de comportamento, assim como a uma elevada auto-estima por parte da criança e percepção mais positiva de seu ambiente familiar. 
De acordo com Cunningham, Reuler, Blackwell e Deck (1981), as crianças menos responsivas podem ter dificuldades em prover aos adultos informações suficientes, tais como o nível de linguagem que elas podem compreender, e os adultos, consequentemente, podem ter dificuldades em ajustar sua complexidade lingüística à fala da criança, contribuindo portanto, para a falta de responsividade da mesma.

Entretanto, questiona-se se a competência reside nas crianças ou nas características dos pais, ou se é potencializada na relação; se a criança mais competente desperta interações mais responsivas que as crianças menos competentes; e se os pais intelectualmente mais competentes transmitem esta competência geneticamente para seus filhos. Desta forma, as relações responsivas correspondem a um epifenômeno e não a uma causa, necessitando, então, que seja analisada sob uma perspectiva interacional, considerando-se os vários aspectos que circundam a relação da criança com o seu meio (Beckwith \& cols., 1992).

Quanto aos estilos de input que podem interferir negativamente no desenvolvimento da linguagem, um dos mais citados é a diretividade. Segundo Nelson (1973, citado em Rice, 1989), quando este estilo de inputé operacionalizado como comandos, direções e instruções, está associado a uma aquisição mais lenta de nomes e palavras por parte das crianças que o recebem e, conforme Hampson e Nelson (1993), está associado a um desenvolvimento mais lento da linguagem da criança.

A diretividade apresenta-se também associada à baixa responsividade. Num estudo longitudinal realizado por Beckwith e colaboradores (1992), com uma amostra de 44 díades mãe-criança de 24 meses de idade e falantes da língua inglesa, os resultados mostraram que as mães mais controladoras com seus filhos aos 24 meses de idade, apresentavam-se menos responsivas aos mesmos no início da adolescência.

Outro aspecto considerado da diretividade é que, conforme Snow (1996), este é um estilo de inputcaracterístico das mães de crianças atípicas. Nessa mesma linha de pensamento, Gallaway e Woll (1994) e Conti-Ramsden (1994) ressaltam que as crianças atípicas com Síndrome de Down e crianças com distúrbios específicos de linguagem são menos ativas e menos comunicadoras espontâneas, o que leva a supor que a diretividade dos pais pode ser uma compensação inevitável para a passividade e falta de compreensão ou baixa responsividade da criança.

Por outro lado, Pine (1992) questiona o estereótipo negativo (intrusividade, insensibilidade) atribuído ao estilo de fala diretiva. Segundo esse autor, tal estereótipo reflete o valor cultural definido em termos de estilos orientados para o comportamento e estilos orientados para a linguagem, fato que indica uma visão unidimensional (facilitador $\mathrm{x}$ inibidor) da diretividade.

Em conseqüência, as diferentes formas de estilos diretivos são tratados como equivalentes, o que representa, de acordo com Pine (1992), um mal entendido. Pine argumenta que diferentes estilos diretivos podem refletir diferentes intenções comunicativas, a exemplo da diretividade atencional e da diretividade comportamental.

No intuito de reavaliar essa caracterização negativa da diretividade, Pine (1992) realizou um estudo longitudinal com 8 díades mãe-criança primogênita, sendo 5 meninas e 3 meninos, na faixa etária de 11 meses a 1 ano e 8 meses, de classe média, e observou que os estilos diretivos atencional e comportamental podem realmente representar dois fenômenos diferentes, uma vez que houve uma baixa correlação entre $\operatorname{ambos}(r=-0,10$, n.s $)$. Esse autor observou ainda que a diretividade atencional parece refletir sensibilidade materna aos interesses da criança, evidenciando que alguns aspectos da diretividade podem ser propiciadores do desenvolvimento da linguagem.

Segundo Barnes e colaboradores (1983), os estilos diretivos devem ser analisados à luz da idade da criança, uma vez que o controle sobre o comportamento da mesma nos estágios mais tardios do seu desenvolvimento é mais provável de restringir sua aquisição lingüística. Por outro lado, nas idades mais precoces, os diretivos estão associados com o progresso da linguagem da criança, como mostrado pelos resultados do estudo desses autores.

Estas incoerências acerca do papel da diretividade devemse, em parte, ao fato de não haver um consenso em sua conceituação, levando cada autor a defini-la segundo suas propostas de análise. Ademais, os efeitos da diretividade não devem ser interpretados de forma direta, uma vez que aspectos desse estilo de fala podem desempenhar diferentes papéis na comunicação entre os pais e suas crianças aprendizes da linguagem (Salomão \& Conti-Ramsden, 1994).

Enfim, mesmo apontando os estilos de input favoráveis e desfavoráveis à aquisição da linguagem, a abordagem da interação social dos estudiosos da linguagem não postula que o input por si só seja responsável pelo desenvolvimento da linguagem, considerando que os fatores biológicos também são importantes neste processo. Entretanto, a forma como a criança interage com o meio social e a qualidade das informações que recebe são fatores importantes para o domínio da linguagem. Se ela tem maiores oportunidades de interagir socialmente e se é considerada uma participante ativa desta interação, provavelmente alcançará com mais eficácia o domínio da linguagem do que aquelas crianças que não tiveram esta oportunidade e não foram consideradas como tal. 
É necessário ressaltar que, apesar do input ser considerado pelas teorias interacionistas como um fator importante na aquisição lingüística, a ênfase demasiada sobre ele, no estudo da linguagem, tem sido criticada por alguns teóricos, como os cognitivistas e os inatistas. Quanto aos cognitivistas, podese mencionar a crítica de Slobin (1980), cujo argumento refere-se ao fato do input não desempenhar nenhum papel na formação de conceitos. Segundo ele, este papel seria desempenhado apenas pela cognição.

Em contrapartida, Schlesinger (1977), argumenta que “o aprendizado da linguagem não depende apenas de capacidades cognitivas gerais, mas também de uma categorização de objetos e eventos, que se faz necessária para falar e compreender uma língua” (p. 104). Para esse autor, é através de uma complexa interação entre o desenvolvimento cognitivo e o input lingüístico que se formam os conceitos que subjazem ao uso da língua.

A crítica dos inatistas (Chomsky, 1998) ao imput lingüístico repousa no fato dos dados lingüísticos primários provindos do ambiente, ou seja, a fala que a criança ouve, são limitados e deformados, e a criança é capaz de produzir e interpretar, em contextos apropriados, enunciados que nunca ouviu antes (Slobin, 1980).

$\mathrm{O}$ argumento utilizado pelos inatistas é que os adultos não corrigem os erros gramaticais de seus filhos, logo a aprendizagem da fala gramaticalmente correta depende de fatores inatos. Por outro lado, estudos realizados por Hirsh-Pasek e colaboradores (1984) demonstraram que os pais podem expressar respostas aos erros gramaticais de seus filhos de uma forma mais sutil, ou indireta, fato que eles denominaram de "evidência negativa". Esses autores observaram que as mães repetiam mais aos enunciados gramaticalmente incorretos de seus filhos, e estas repetições continham correções dos erros.

Corroborando os resultados encontrados por HirshPasek e colaboradores (1984), Post (1993) observou em seu estudo que as mães repetiam de forma exata os enunciados bem elaborados da criança, traduzindo a idéia de que estes têm sido entendidos pela mãe. Verificou também que essas mães repetiam os enunciados mal elaborados da criança, estendendo-os, expandindo-os ou reformulando-os, o que pode representar uma tentativa de mostrar-lhe que seu enunciado não está correto e precisa ser melhorado. Desta forma, através do feedback implícito a mãe oferece à criança a versão correta de seu enunciado.

Enfim, os estudos acima mencionados implicam que se faz necessário reexaminar as teorias cujos pressupostos consideram que as crianças não recebem correções de seus enunciados incorretos. Implicam ainda, que o input lingüístico é importante para o processo de aquisição da linguagem e que as crianças parecem capacitadas a fazer uso desse input para o avanço de suas habilidades lingüísticas.

Segundo Snow (1977), o reconhecimento de que a criança tem capacidade para entender o que o adulto fala, e a insistência da mãe em introduzir um modelo conversacional em suas interações com a criança podem ajudar a explicar como esta adquire, desde cedo, a habilidade de ocupar um lugar na conversação e em outros tipos de interação. Esta participação da criança na conversação desempenha, portanto, um importante papel no comportamento materno.

\section{Considerações Finais}

Em resumo, observa-se que a perspectiva da interação social dos estudiosos da linguagem enfatiza o papel desempenhado pelo input lingǘstico no processo de aquisição da linguagem infantil, o qual, por sua vez, precisa ser analisado à luz das características individuais e dos aspectos sociais relacionados à criança e ao adulto, tornando necessária uma análise interacional e bidirecional desta relação. A importância de se levar em conta tais características encontrase no fato de que existe variabilidade de uma criança para outra, de uma mãe para outra, na forma e na medida em que ministram e fazem uso de aspectos particulares da linguagem. Ademais, segundo Pine (1994), o nível de desenvolvimento da criança, em termos de idade ou de estágio lingüístico, influencia a forma como ela fará uso do input recebido; um determinado estilo de input materno poderá ter efeitos facilitadores da linguagem em um nível de desenvolvimento da criança, e não apresentar esse mesmo efeito em um outro nível.

É importante mencionar ainda que existem variações no contexto sociocultural em que os indivíduos vivem. A variação entre contextos é marcada pelos diferentes modelos de uso da linguagem que o meio social oferece. Estes modelos são apresentados segundo os modos de vida e os tipos de interações típicas do meio social dos indivíduos, ou seja, correspondem a seus hábitos e necessidades adaptativas.

Por fim, todos esses aspectos são enfatizados pela teoria da interação social, que busca romper o dualismo natureza versus ambiente que prevaleceu por tanto tempo nas explicações sobre a aquisição da linguagem. Os pressupostos dessa teoria contribuem para uma análise do conhecimento acerca do contexto sociocultural em que o indivíduo está inserido, permitindo uma articulação deste com as características individuais do adulto e da criança, orientado por um modelo bidirecional, através do qual evidenciam-se a reciprocidade e a adaptação mútua entre $\mathrm{o}$ adulto e a criança. 


\section{Referências}

Aimard, P. (1986). A linguagem da criança. Porto Alegre: Artes Médicas.

Austin, J. L. (1990). Quando dižer éfazer. Porto Alegre: Artes Médicas. (Original publicado em 1952)

Barnes, S., Gutfreund, M., Satterly, D. \& Wells, G. (1983). Characteristics of adult speech which predict children's language development. Journal of Child Language, 10, 65-84.

Bates, E., Dale, P. S. \& Thal, D. (1997). Diferenças individuais e suas implicações para as teorias do desenvolvimento da linguagem. Em P. Fletcher \& B. MacWhinney (Orgs.), Compêndio da linguagem da criança (pp. 87-130). Porto Alegre: Artes Médicas.

Beckwith, L., Rodning, C. \& Cohen, S. (1992). Preterm children at early adolescence and continuity and discontinuity in maternal responsiveness from infancy. Child Development, 63, 1198-1208.

Bruner, J. S. (1983). Child's talk: Learning to use language. New York: Norton.

Bruner, J. S. (1997). Atos de significação. Porto Alegre: Artes Médicas.

Chomsky, N. (1973). Linguagem e pensamento. Petrópoles, RJ: Vozes.

Chomsky, N. (1998). Linguagem e mente: Pensamentos atuais sobre antigos problemas. Brasília: Editora da UNB.

Conti-Ramsden, G. (1990). Maternal recasts and other contingent replies to language-impaired children. Journal of Speech and Hearing Disorders, 55, 262274.

Conti-Ramsden, G. (1994). Language interaction with atypical language learners. Em C. Gallaway \& B. Richards (Orgs.), Input and interaction in language acquisition (pp. 183-198). Londres: Cambridge University Press.

Cunningham, C. E., Reuler, E., Blackwell, J. \& Deck, J. (1981). Behavioral and linguistic developments in the interactions of normal and retarded children with their mothers. Child Development, 52, 62-70.

Damast, A. M., Tamis-LeMonda, C. S. \& Bornstein, M. H. (1996). Mother- child play: Sequential interactions and the relation between maternal beliefs and behaviors. Child Development, 67, 1752-1766.

Demetras, M., Post, K. \& Snow, C. (1986). Feedback to first language learners. Journal of Child Language, 13, 275-292.

Ely, R. \& Gleason, B. (1996). Socialization across contexts. Em P. Fletcher \& B. Macwhinney (Orgs.), The handbook of child language (pp. 251-270). Oxford, U.K.: Blackwell.

Fagot, B. A. \& Hagan, R. (1991). Observations of parental reactions to sexstereotyped behaviors: Age and sex effects. Child Development, 62, 617-628.

Furrow, D., Nelson, K. \& Benedict, H. (1979). Mothers' speech to children and syntactic development: Some simple relationships. Journal of Child L anguage, 6, 423-442.

Gallaway, C. \& Woll, B. (1994). Interaction and childhood deafness. Em C. Gallaway \& B. Richards (Orgs.), Input and interaction in language acquisition (pp. 197-218). London: Cambridge University Press.

Garton, A. F. (1992). Social interaction and the development of language and cognition. Hillsdale, USA: Lawrence Erlbaum.

Gleitman, L., Newport, E. \& Gleitman, H. (1984). The current status of the motherese hypothesis. Journal of Child Language, 11, 43-79.

Hampson, J. \& Nelson, K. (1993). The relation of maternal language to variation in rate and style of language acquisition. Journal of Child Language, 20, 313342.

Hirsh-Pasek, K, Treiman, R. \& Schneiderman, M. (1984). Brown and Hanlon revisited: Mother's sensitivity to ungrammatical forms. Journal of Child Language, 11, 81-88.

Hoff-Ginsberg, E. (1991). Mother-child conversation in different social classes and communicative settings. Child Development, 62, 782-796.

Hoff-Ginsberg, E. \& Schatz, M. (1982). Linguistic input and the child's acquisition of language. Psychological Bulletin, 92, 3-26.
Lieven, E. V. M. (1994). Crosslinguistic and crosscultural aspects of language addressed to children. Em C. Gallaway \& B. J. Richards (Orgs.), Input and interaction in language acquisition (pp. 56-73). London: Cambridge University Press

Luque, A. \& Villa, I. (1995). Aquisição da linguagem. Em C. Coll, J. Palácios \& A . Marchesi (Orgs.), Desenvolvimento psicológico e educação (Vol. 1, pp. 149-164). Porto Alegre: Artes Médicas.

McCabe, A. \& Peterson, C. (1991). Getting the story: A longitudinal study of parental styles in eliciting personal narratives anda developing narrative skill. Em A. McCabe \& C. Petersnon (Orgs.), Developing narrative structure (pp. $217-$ 253). Hillsdale, NJ: Lawrence Erlbaum.

Maratsos, M. (1983). Some current issues in the study of the acquisition of grammar. Em P. H. Mussen (Org.), Handbook of child psychology: Cognitive development (pp. 730-738, Vol. 3). New York: Willey.

Nelson, K. E. (1977). Facilitating children's syntax acquisition. Developmental Psychology, 13, 101-107.

Nelson, K. E., Welsch, J., Camarata, S. M., Butkovsky, L. \& Camarata, M. (1995). Available input for language impaired children and younger children of matched language levels. First Language, 15, 1-17.

Phillips, J. R. (1973). Syntax and vocabulary of mother's speech to young children: Age and sex comparisons. Child Development, 44, 182-185.

Pine, J. M. (1992). Maternal style at the early one-word stage: Re-evaluating the stereotype of the directive mother. First Language, 12, 169-186.

Pine, J. M. (1994). The language of primary caregivers. Em C. Gallaway \& B. J. Richards (Orgs.), Input and interaction in language acquisition (pp. 15-37). London: Cambridge University Press.

Post, K. N. (1993). Negative evidence in the language learning environment of laterborns in a rural Florida community. Em J. Sokolov \& C. Snow (Orgs.), Handbook of research in language development using CHILDES (pp. 132-173). Hillsdale, NJ: Lawrence Erlbaum.

Rice, M. L. (1989). Children's language acquisition. American Psychologist, 44, 149156.

Scarr, S. \& Eisenberg, M. (1993). Child care research: Issues, perspectives, and results. Annual Review of Psychology, 44, 613-644.

Salomão, N. M. R. (1996). Interaction between mothers and cbildren with specific language impairment: A longitudinal study. Tese de Doutorado não-publicada, Curso de Pós-Graduação em Psicologia. University of Manchester: England.

Salomão, N. M. R. \& Conti-Ramsden, G. (1994). Maternal speech to their offspring: SLI children and their younger siblings. Scandinavian Journal of Logopedios and Phonology, 19, 11-17.

Schlesinger, I. N. (1977). The role of cognitive development and linguistic input in language acquisition. Journal of Child Language, 4, 153-169.

Searle, J. R. (1995). Intencionalidade. São Paulo: Martins Fontes. (Original publicado em 1969)

Sheppard, W. C. \& Willoughby, R. H. (1975).Child behavior learning and development. Chicago: Rand McNally College.

Slobin, D. J. (1980). Psicolingüistica. São Paulo: Nacional.

Snow, C. E. (1972). Mothers' speech to children learning language. Child Development, 43, 549-565.

Snow, C. E. (1977). The development of conversation between mothers and babies. Journal of Child Language, 4, 1-22.

Snow, C. E. (1989). Understanding social interaction and language acquisition; sentences are not enough. Em M. Bornstein \& J. S. Bruner (Orgs.), Interaction in buman development (pp. 83-103). Hillsdale, NJ: Lawrence Erlbaum.

Snow, C. E. (1996). Issues in the study of input: Fine-tuning, universality, individual and developmental differences, and necessary causes. Em P. Fletcher \& B. Macwhinney (Orgs.), The handbook of child language (pp. 180-193). Oxford, U.K.: Blackwell. 
Sokolov, J. L. \& Snow, C. E. (1994). The changing role of negative evidence in theories of language development. Em C. Gallaway \& B. J. Richards (Orgs.), Input and interaction in language acquisition (pp. 38-55). London: Cambridge University Press.

Vandell, D. L. \& Wilson, K. S. (1987). Infants' interactions with mother, sibling, and peer: Contrasts and relations between interaction systems. Child Development, 58, 176-186.

Villa, I. (1995). Aquisição da linguagem. Em C. Coll, J. Palácios \& A. Marchesi (Orgs.), Desenvolvimento psicológico e educação (Vol. 1, pp. 69-80). Porto Alegre: Artes Médicas.
Vygotsky, L. S. (1984). A formação social da mente. São Paulo: Martins Fontes. (Original publicado em 1978)

Sobre as autoras

Lucivanda Cavalcante Borges é Psicóloga, Mestre em Psicologia Social pela Universidade Federal da Paraíba. É Professora do Curso de Psicologia da Universidade Tirandentes (SE).

Nádia Maria Ribeirão Salomão é Mestre em Educação Especial pela Universidade Federal de São Carlos. É Doutora em Psicologia pela Manchester University (Ingalterra). É Professora do Programa de Pós-Graduação em Psicologia Social da Universidade Federal da Paraíba. 